\title{
Navigating the Unprecedented: Working Remotely Unexpectedly ${ }^{1}$
}

\author{
Megan Stein and Matthew Sowcik ${ }^{2}$
}

\section{Introduction}

When disaster strikes and fundamental changes to your work environment happen, maintaining the expectations of your job while transitioning your day-to-day responsibilities to remote work can present unique challenges. Working from an alternative location can be a daunting adjustment when there is no time to prepare for the transition. Ensuring personal well-being and productivity through unexpected times takes a proactive partnership from both the employer/supervisor and employee. The first step to facilitate adjustment in times of uncertainty is identifying the aspects of your role that will differ in a new working environment. Next, you can proactively identify strategies to maintain productivity and prepare for potential personal challenges when parts or all of your career are unexpectedly transitioned to your new work environment.

\section{How are remote and in-office work different?}

Aside from the obvious distinction of work location, there are noticeable differences when working remotely and working from your office. One of the most commonly reported challenges is the lack of social interaction with colleagues (Koehne et al., 2012). Employees suddenly working from home can often feel disconnected and lonely (Gardner \& Matviak, 2020). Feelings of isolation may be created or heightened when this transition happens due to an unexpected event. While working from home in general is proven to enhance workplace productivity, a shift in location that happens due to necessity rather than choice can decrease productivity (Koehne, Shih, \& Olson, 2012). While both environments have a unique set of circumstances, personal career success and satisfaction are instrumental to both the organization and employee, and they can be found in any location.

\section{Best Practices for Remote Personal Well-Being}

Maintaining personal well-being in times of crisis is fundamental to being successful. Finding a way to balance your career and other responsibilities while dealing with an external challenge can be intimidating. The following best practices can help you navigate your personal well-being in times of unprecedented change:

- Stick to a schedule: A sudden shift in workplace location can be disruptive to daily schedules and plans. According to Wingard (2020), setting a strict schedule of when you are working helps prevent burnout from eager employees. Some may find it challenging to turn work "off" when there is no distance between the office and home. Allow for time to relax and unwind as you would when you come home from your office. Others may find it challenging to turn work "on" when there is too much distance between the office and home. Having a routine schedule

1. This document is AEC692, one of a series of the Department of Agricultural Education and Communication, UF/IFAS Extension. Original publication date March 2020. Visit the EDIS website at https://edis.ifas.ufl.edu for the currently supported version of this publication.

2. Megan Stein, lecturer, and Matthew Sowcik, assistant professor, Department of Agricultural Education and Communication, UF/IFAS Extension, Gainesville, FL 32611.

The Institute of Food and Agricultural Sciences (IFAS) is an Equal Opportunity Institution authorized to provide research, educational information and other services

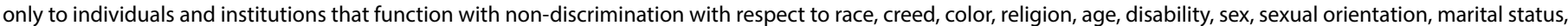

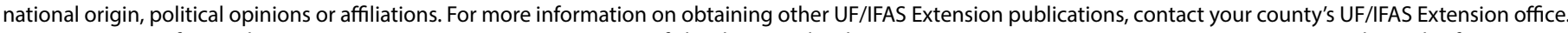
U.S. Department of Agriculture, UF/IFAS Extension Service, University of Florida, IFAS, Florida A \& M University Cooperative Extension Program, and Boards of County Commissioners Cooperating. Nick T. Place, dean for UF/IFAS Extension. 
can allow employees to maintain productivity and work output.

- Designate a working location: To help yourself distinguish between work and your new remote work location, find a location where you feel you can be productive (Robinson, 2020). Use this location, whether it be a home office, kitchen table, or patio, each time you are accomplishing work-related tasks.

- Minimize distractions: Treat the time you are scheduled to be at work as if you are still working from your office. While it can be tempting to complete personal tasks such as doing laundry or washing dishes if you are working from home, be sure you are using your time wisely, even if household tasks are unfinished. To maintain structure in your day, it is important for you to create an environment that reflects your traditional work space as much as possible.

- When the workday is over, put work-related items out of sight: Allowing yourself to distance your home from your work is pivotal to avoid burnout related to working remotely (Wingard, 2020). Ensure your daily routine includes packing up all work-related materials and putting them in a private location until the next time you are scheduled to work. For instance, if your remote-work environment is your kitchen table, remove your laptop and books after you have finished working for the day.

- Schedule social events with work colleagues via technology: To prevent feelings of disconnect that can accompany working remotely, be sure to set aside time to check in and catch up with your colleagues (Gardner \& Matviak, 2020). Checking in with colleagues who are working remotely allows for individuals to feel more connected to your organization (Grenny \& Maxfield, 2017). Use videoconferencing tools to set up a weekly time for casual conversation. It is much easier to cancel a scheduled conversation to catch up then to try to gather individuals together for a check-in at the last minute. For example, if you usually take a ten-minute break to go on a walk with your colleague, do the same remotely and communicate via video-chat while you go on your walk together.

- Identify your personal well-being options: Many organizations have formal resources available to their employees to help in times of need. For example, one option may be the opportunity to maintain your physical health in times of crisis through a virtual gym membership. Other programs may exist to help with mental health, like counseling or personal development opportunities. If these resources are something you are not familiar with or something you did not feel like you needed in the past, this is an excellent time to familiarize yourself with options that are available to you.

\section{Best Practices for Remote Productivity}

As priorities shift in times of crisis, career productivity may be a priority that presents unique challenges. However, maintaining a similar work structure and setting achievable goals can be an excellent way to navigate rapid, unexpected adjustments. Best practices have been identified to help you maintain productivity in times of unprecedented change:

- Make sure your technological needs are met: Technological needs have the potential to vary greatly among individuals within an organization. Work closely with your organization to ensure you have all the materials, software, and technology needed to perform your tasks as efficiently and effectively as if you were in your office. If there are tasks that require specialized equipment, ensure you are communicating with your supervisor about tasks that may be more challenging to accomplish while working remotely.

- Prepare for technological challenges: Be prepared for other unexpected circumstances that may push your technological capacity to its limit (children going to school remotely, a partner also working remotely, other family members using the internet simultaneously, etc.). Identify tasks that may not be feasible from your alternative work location. Make a proactive plan to ensure tasks are accounted for if they are unable to be performed remotely.

- Be mindful of others: Your circumstances do not match your colleagues. Extend grace to those who may not have an office to seclude themselves in, parents whose children are requiring assistance during a videoconference, or coworkers who are having a challenging time adjusting to unfamiliar software and technologies (Gardner \& Matviak, 2020). Maintaining a balance of synchronous and asynchronous options when scheduling allows for each colleague's needs to be addressed (Malhotra et al., 2007). Being cognizant and respectful of each person's circumstances is the best way to maintain trust and respect with your colleagues.

- Ensure your priorities match your job description: A sudden shift in work environment is a great time to reevaluate priorities (Gardner \& Matviak, 2020). Identify the most important tasks, and ensure they align with your organization's mission and goals. If your role is independent, ensure that new tasks you are creating or taking on 
are meaningful towards helping your organization reach its goals. If your role requires you to work closely with others, check in with teammates to ensure you are all moving in the same direction on collaborative tasks.

- Set realistic goals: Be sure the goals you are setting align with what you can accomplish in your new environment. Items that are realistic for your in-office work environment may take longer or require different elements when working remotely. Setting realistic, short-term goals is an effective way to maintain momentum in times of rapid change. If your role allows you to work closely with others, communicate with your teammates if deadlines need to be updated or pushed back. Communication is key when adjusting to a core organizational shift (Gardner \& Matviak, 2020).

- Collaborate: Be open to maintaining collaborative relationships or starting new ones. Working well with colleagues you have established relationships with is a great way to maintain normalcy through times of disaster. If your entire organization has gone remote, use this as a unique opportunity to open the potential for new collaborations. As schedules readjust, reach out to colleagues you believe can enhance your work and find areas to collaborate.

- Ask for help: When faced with unprecedented times, it is unrealistic to think you can accomplish everything alone. Ask for help from those around you in your organization. Major adjustments are challenging for everyone to navigate. It is expected for you to ask for assistance, help, or favors as individuals adjust in times of uncertainty. If you are struggling, or think a coworker could use help, this is an excellent time to reach out to your teammates.

\section{Conclusion}

A sudden shift in workplace conditions can be disruptive and challenging. Team members will need to make adjustments that are unique to them and their role in your organization. Through appropriate assessment of the change and proactive adjustment strategies, team members can learn to manage their personal well-being while maintaining productivity. A strong partnership between employees and their employers allow organizational goals to be accomplished through unprecedented times.

\section{References}

Gardener, H., \& Matviak, I. (2020). Coronavirus

could force teams to work remotely. Harvard

Business Review. https://hbr.org/2020/03/

coronavirus-could-force-teams-to-work-remotely

Grenny, J., \& Maxfield, D. (2017). A study of 1,100

employees found that remote workers feel shunned and left out. Harvard Business Review. https://hbr.org/2017/11/astudy-of-1100-employees-found-that-remote-workers-feelshunned-and-left-out

Koehne, B., Shih, P. C., \& Olson, J. S. (2012). Remote and alone: Coping with being the remote member on the team. Proceedings of the ACM 2012 Conference on Computer Supported Cooperative Work, 1257-1266. https://dl.acm. org/doi/pdf/10.1145/2145204.2145393

Malhotra, A., Majchrzak, A., \& Rosen, B. (2007). Leading virtual teams. Academy of Management Perspectives, 21(1), $60-70$.

Robinson, B. (2020). 9 tips to be productive when working at home during COVID-19. Forbes. https://www.forbes. com/sites/bryanrobinson/2020/03/14/9-tips-to-beproductive-when-working-at-home-during-covid-19

Wingard, J. (2020). Leading remote workers: The Coronavirus' impact on effective management. Forbes. https://www. forbes.com/sites/jasonwingard/2020/03/13/team-workingat-home-because-of-coronavirus-heres-how-to-lead-themeffectively 